Arab World English Journal (AWEJ) Volume 12. Number2 June 2021

Pp. 222-237

DOI: https://dx.doi.org/10.24093/awej/vol12no2.15

\title{
Iraqi Kurd EFL Learners' Uses of Conjunctive Adverbials in Essays
}

\author{
Awder Raza Aziz \\ Translation Techniques Department, Sulaimani Technical Institute \\ Sulaimani Polytechnic University \\ Sulaymaniyah, Iraq \\ \&
}

English Department, Komar University of Science and Technology, Sulaimani, Iraq

Rebaz Bahadeen Mohammed Nuri

Translation Techniques Department, Sulaimani Technical Institute,

Sulaimani Polytechnic University

Sulaymaniyah, Iraq

Received: 3/29/2021

Accepted: 5/6/2021

Published:6/24/2021

\begin{abstract}
The quality of any academic essay highly depends on cohesion and coherence since they affect the overall quality and the tone of the writing to a great extent. Conjunctive adverbials are among the types of devices which logically help linking sentences into paragraphs and paragraphs into essays. Conjunctive Adverbials ultimately affect the cohesion and coherence of any piece of writing. This paper investigates conjunctive adverbials in essays written by Iraqi Kurd EFL learners at the undergraduate level. It explicitly attempts to discover what specific conjunctive adverbials types are overused, underused, or misused and in what positions in sentences. A learner corpus of 50 complete essays was compiled for this study. The findings showed that the participants tended to use more sequential and additive conjunctive adverbials than adversative and causals. Additionally, the results demonstrated that the learners relied heavily on a limited number of conjunctive adverbials, mainly in the initial position. However, the conjunctive adverbial category affects its place in the sentence.

Keywords: Academic writing, adverbial conjuncts, corpus study, discourse markers, Kurd EFL learners
\end{abstract}

Cite as: Aziz, A.R., \& Nuri, R. B. M. (2021). Iraqi Kurd EFL Learners' Uses of Conjunctive Adverbials in Essays. Arab World English Journal, 12 (2) 222-237.

DOI: https://dx.doi.org/10.24093/awej/vol12no2.15 


\section{Introduction}

Writing is not one of the easy skills of language learning and teaching to master as a skill. English as a Foreign Language (EFL) learners and instructors need to study this skill extensively. Alsharif (2017) notes writing is neither easy for the instructors nor the students. Apart from some other aspects, one of the elements that affect the quality of a piece of writing is cohesion and coherence, especially in second language writing ( Rustipa, 2013; Güneş, 2017). Rustipa (2014) states that when someone writes, they have to write excellent sentences and organize them logically into paragraphs and essays. Xu \& Liu (2012) found that the lack of cohesion and coherence is one reason why Chinese student writings are less persuasive.

It also seems there is a consensus among the researchers that one of the aspects to achieve cohesion and coherence is through the proper use of conjunctive adverbials (Qaddumi, 1995; Celce-Murcia \& Larsen-Freeman, 1999; Rustipa, 2014; Sabzevari, Haghverdi, \& Biria, 2016; Alsharif, 2017; Güneş, 2017; An \& Xu, 2018).

Additional terms, definitions, and categorizations were found for conjunctive adverbials. Other terms were found in previous papers about conjunctive adverbials, for instance, "conjuncts" (Quirk, et al. , 1985, p.47), adverbials (Biber, et al., 1999, p.762; Sabzevari et al., 2016) "conjunctive adverbials" (Chen, 2006, p.113; Xu \& Liu, 2012; Park, 2013), "linking adverbials" (Peacock, 2010; Lei, 2012; Güneş, 2017), "connectives" (Salih, 2014), "logical connectors" (Wu, 2019), "adverbial connectors" (Tankó, 2004; Alsharif, 2017; Lee, 2013 or even 'cohesive devices' by Celce-Murcia \& Larsen-Freeman (1999). All terms referred to the same set of words used by learners, researchers, or writers when the researchers explored the terms in writings written by authors or students. The current paper uses Conjunctive Adverbials (CAs) for the purpose of clarity.

There are also different definitions for CAs. Conrad (1999) defines linking adverbials as "those adverbials that serve to connect two stretches of discourse" (p.3). At the same time, CelceMurcia \& Larsen-Freeman (1999) and Biber et al. (1999) define them as words that add no semantic content by themselves but are only logical connectors that can function as signposts and make explicit the relationship between two units of discourse. Most researchers agree that these expressions do not add any semantic content to sentences; However, as Quirk et al. (1985) note, CAs contribute to the clarity and comprehensibility of a text, and Biber et al. (1999) argue that they can also express the speakers' or the writers' stance towards the clause. When they are appropriately used, it is easier for the readers to understand the logical connection between the discourse units. Yang (1989) claims, in speaking, using pronunciation features, logical connections can be made between the units of discourse; However, as pronunciation features are absent in writing, CAs are used to show that logical connection. Conjunctive adverbials connect sentences, paragraphs, and even multiple paragraphs. CAs, therefore, are words or maybe groups of words, which have different registers and depend on context, that are used primarily in writing that make a logical link between the sentences and help the overall clarity of a piece of writing without adding any semantic content. Proper use of CAs enables a piece of text to look and sound more linked and coherent.

These words are categorized in different ways depending on their semantic content and features. Halliday \& Hasan (1976) organized CAs into additive, adversative, causal, and 
temporal. Meanwhile, based on their semantic functions, Quirk et al. (1985) categorized them into listing, summative, appositive, resultive, inferential, contrastive, and transitional. Quirk et al.'s (1985) list, however, is not precisely accurate. As Xu \& Liu (2012) suggested, a word such as thus, depending on the context, can be listed under summative, appositive, and resultive. Also, relying on Halliday \& Hasan's (1976) classification, Celce-Murcia \& Larsen-Freeman (1999) divided and categorized these adverbials into additive, adversative, causal, and temporal. Likewise, contributing to Celce-Murcia \& Larsen-Freeman's (1999) categorization, Liu (2008) divided CAs into four main categories: additive, adversative, causal/resultative, and sequential, and he also provided a list of thirteen subcategories and a comprehensive list of 110 examples of adverbials. In this study, Liu's (2008) taxonomy was taken as a reference since it was the most comprehensive and up-to-date list. Table 1 shows Liu's (2008) list of CAs.

Table 1. Liu's (2008) List of CAs

\begin{tabular}{|c|l|l|}
\hline Category & Subcategory & Examples \\
\hline \multirow{4}{*}{ Additive } & Emphatic & Besides \\
\cline { 2 - 3 } & Appositional/reformulation & For example \\
\cline { 2 - 3 } & Similarity comparative & Likewise \\
\hline \multirow{4}{*}{ Adversative } & Proper adversative/concessive & However \\
\cline { 2 - 3 } & Contrastive & In fact \\
\cline { 2 - 3 } & Correction & Instead \\
\cline { 2 - 3 } & Dismissal & In any case \\
\hline \multirow{3}{*}{ Causal/Resultative } & General causal & As a result \\
\cline { 2 - 3 } & & \\
\cline { 2 - 3 } & Conditional causal & In that case \\
\hline \multirow{3}{*}{ Sequential } & Enumerative/listing & First/firstly \\
\cline { 2 - 3 } & Simultaneous & To summarise \\
\cline { 2 - 3 } & Summative & By the way \\
\cline { 2 - 3 } & Transitional to another topic & samale \\
\hline
\end{tabular}

There are usually three positions for CAs in sentences: initial, medial, and final position (Tufte, 2006). When used in the initial position, as Tufte (2006) argues, CAs connect or contrast the new sentence with its predecessors and reduce repetition. Previous research papers suggested that the initial position is the most commonplace for CAs (Güneş, 2017; Xu \& Liu, 2012; An \& $\mathrm{Xu}, 2018$; Yilmaz \& Dikilitas, 2017). Irrelevance to what position they are used in, CAs are noticeable cohesive devices that can affect the cohere and unity of any piece of writing, especially essays. Meanwhile, EFL learners of the English language make mistakes while using these cohesive devices. Previous literature suggested there is a tendency to overuse, underuse, or misuse them in their writings (Granger \& Tyson, 1996; Lei, 2012; Sabzevari et al., 2016).

\section{Statement of the Problem}

It seems CAs profoundly affect the overall clarity and coherence of any piece of writing. They might even affect the efficacy of communication (Blackemore, 1987). Notwithstanding, learners make mistakes using these CAs. Students usually overuse, misuse, or use these CAs in the wrong place in the sentence.

\section{Significance of the Study}


The significance of the study lies in contributing to the field of corpus linguistics. Additionally, to the best of the researchers' knowledge, this study is the first corpus-based study of CAs that Kurd EFL learners use in essays at the undergraduate level. Previous studies have examined EFL learners' use of CAs in Sweeden (Altenberg \& Tapper, 1998), Hong Kong (Milton \& Tsang, 1993), Korea (Lee, 2013; Park, 2013), Saudi Arabia (Alsharif, 2017), Hungary (Tankó, 2004), Taiwan (Chen, 2006), and China (An \& Xu, 2018; Lei, 2012). Thus, this fills the gap in applied linguistics, particularly in the domain of CAs in the academic writing of Kurd EFL learners based on a corpus approach.

\section{Purpose of the study}

The present paper explores the use of conjunctive adverbials by undergraduate Kurd EFL learners. It explicitly studies what CAs are more preferred and in what position. Fifty essays written by Kurd EFL learners will be analyzed to discover the type of CAs, place, and frequency of each specific CA. The paper aims to find whether Kurd EFL learners overuse, underuse, or inappropriately use CAs. The results of the study will also be compared with other research about different first language backgrounds. Therefore, the results of this study might have some theoretical and practical implications for instructors who teach academic writing.

\section{Research Questions}

1. What category of conjunctive adverbials are more preferred by Kurd EFL learners?

2. In what position are conjunctive adverbials found?

3. Are there any conjunctive adverbials that are overused or underused?

\section{Delimitations of the Study}

The present study has limitations. One of them emerges from the relatively small size of the corpus which was compiled for this study. It was mainly comprised of essays written by Kurd EFL learners in the city of Sulaimani, Iraq. First-year students were excluded since they had not been instructed about academic essay writing in English.

\section{Literature Review}

Using different methods and approaches, researchers have studied the use of CAs by different first language backgrounds. Some researchers studied adverbials in speaking (Wu, 2019). In contrast, most of the other studies found were journal articles, student writings, or comparisons between the use of CAs between different L1 backgrounds to native English speakers.

Some of the researchers studied the use of CAs in published research papers. Peacock (2010) studied the use of CAs in 320 published research articles across eight disciplines. He found that CAs were used extensively in all disciplines to construct and strengthen claims; However, the frequency, form, and function of CAs varied based on the domains of the researchers, scientific fields used more CAs compared to non-scientific disciplines. He also found that contrast, addition, and apposition CAs were the most common types that researchers preferred. Likewise, Gao (2016), using two big corpora, compared CAs in research articles across some scientific fields written by English native speakers and Chinese native speakers. The findings suggested that there was not any significant difference in frequency use of CA use between the two corpora. Despite that, Chinese writers relatively underused additive and adversative CAs 
compared with their English native speaker counterparts. Lei (2012) studied CAs in twenty academic writing dissertations and 120 published articles of Chinese students studying Ph.D. Compared with professional writers, the researcher found that Chinese students relied heavily on a limited number of CAs and additive adverbials followed by sequential and causal/resultative adverbials, accordingly, were overused. Adversative adverbials, on the other hand, were the most problematic and were underused consequently. Güneş (2017) compared 118 English conclusion chapters of Ph.D. dissertations written by native speakers of Turkish to $102 \mathrm{Ph} . \mathrm{D}$. dissertations written by native speakers of English. She found that Turkish native speakers use more linking adverbials compared with their native English counterparts in all subcategories. Additive, causal, and sequential adverbials were overused by native speakers of Turkish while resultative and adversatives were underused.

However, most of the literature was based on studying EFL learners' from various language backgrounds, using CAs in writings.

Crismore (1980) investigated high school and college students' mastery of meaning and use in reading and writing five formal CAs in the English language. In this study, the students were asked to generate sentences using the given CAs (namely still, hence, even so, accordingly, and moreover). The researcher found that students had problems with accordingly and moreover but found still and hence easier to use in sentences. This study did not categorize the CAs based on their use; it merely focused on the use of a very limited number CAs in students' sentences.

Milton \& Tsang (1993) studied Hong Kong students' use of logical connectors using a 4million-word learner corpus. They discovered that many CAs were overused in students' writings; They also listed the top ten overused connectors.

Granger \& Tyson (1996) explored connectors' use by comparing a vast body of words between essays written by native English speakers and French in the English language. He found that the natives' and non-natives' ratio of the use of connectors was very close (1085 for the learners and 1178 for the natives). But he found learners made mistakes in using some CAs, overused some, and underused some others compared with their English counterparts.

$\mathrm{Xu} \&$ Liu (2012) conducted a comparison study using CAs between Chinese EFL learners and native speakers using two corpora. In this study, Chinese students relied heavily on a limited number of CAs, mostly listing, summative, and appositive CAs in the initial position. Native speakers, on the other hand, used more inferential CAs in the medial place. They discovered Chinese students tend to overuse, underuse, and misuse CAs compared with native English speakers. The findings of An \& Xu's (2018) study, in which they studied the use of CAs in 365 pieces of writings by postgraduate Chinese learners, also confirm that Chinese learners use more additive and sequential CAs compared to adversative and causal CAs. Both studies argue that Chinese learners heavily rely on a limited number of CAs regardless of language register.

Using argumentative essays, Park (2013) studied the use of CAs by Korean EFL students in different levels of their language proficiency and compared the findings with a corpus of American students' writings. The researcher found learners from all levels overused CAs, 
sequential, and additives were overused six times more than those of American students. Korean learners also preferred initial positions, especially lower-level learners.

Sabzevari et al. (2016) compared the use of conjunctive adverbs but only in the initial position by Iranian English as a Foreign Language (EFL) and native speakers of English. They analyzed the data on two levels: word level and sentence level. They found that Iranian EFL researchers use more conjunctive adverbials at the word level, whereas native writers use more CAs at the sentence level. The frequency of the adverbials was also found; adversative adverbials were more used in native writers, whereas EFL writers used additives.

Alsharif (2017) studied the use of CAs by Saudi English learners in one hundred essays. She found that Saudi English learners vary adverbials, but they, compared with native speakers, overuse a limited number of CAs while native speakers omitted various CAs. In the same vein, Hussein \& Mudhi (2014) explored the use of CAs by Kuwaiti EFL learners. The findings of Alsharif (2017) and Hussein \& Mudhi (2014) both suggested Arab EFL learners overuse additives and causals whereas underuse adversatives CAs. It was argued that this is a sign of weakness and incompetence of the English language by Arab EFL learners.

However, little is known about Kurd EFL learners. Salih (2014) compared the use of CAs between Kurdish and English language but by using newspaper opinion articles. Also, Suleiman \& Seyyedi (2020) compared using additive adverbials by Kurdish scholars of English and English native speakers in research article papers. They found additives were overused while causals were underused, and medial position was preferred by both Kurdish and English-nativespeaker writers.

The review of the literature shows there is no consistency among the findings of the research studies. It can be inferred different first languages result in different results. Thus, further exploration in this area is vital for Kurd EFL learners and instructors regarding CAs in writings. Against this background, this study aims to find what CAs are more preferred by Kurd EFL learners and in what positions.

\section{Methodology}

This study investigates the use of CAs in English essay writings by Kurd EFL learners at the undergraduate level. The learners were asked to write an essay. The essays were analyzed to answer the research questions stated earlier.

\section{Data Collection}

The present study participants are undergraduate Kurdish learners of English, and Academic Writing is a compulsory course in their second year. The students were given choices to choose a more familiar topic, among several topics, and were asked to write at least 200 words during a two-hour writing session. Fifty essays were collected, mainly about two topics: Namely 'My Country' and 'Best Friend' topics. The reason behind the two-hour sessions was to guarantee that there would be no plagiarism. After the compilation of the essays, they were converted into .txt format since it was recommended by Antconc $(3.4 .4 \mathrm{w})$ software.

\section{Method of Data Analysis}




\section{Quantitative Analysis}

Because of its concise classification, Liu's (2008) list was adopted to explore the use of each category of the CAs. The list is also adopted by some corpus-based studies such as (Güneş, 2017).

Corpus analysis software AntConc (3.4.4w) was used to analyze the data quantitatively. All the adverbials and concordances were extracted from the text using the software. The raw frequency of each CAs was calculated, reported, and analyzed based on the four main categories.

The task of calculating the ratio of occurrence of CAs will be done based on Granger \& Tyson's (1996) method. It estimates the raw frequency of count of the target CA, and then proceeds to calculate a ratio of occurrence based on the frequency of occurrence of CAs per 10,000 words of texts. Comparing this ratio of occurrence, along with its position, with other research paper results helps in determining whether a CA is overused or underused and in what positions.

The researcher divides the total of CAs by the total number of words in the corpus. The results of the calculation are then multiplied by 10,000. This shows the frequency count of CAs per 10,000 in the corpus.

\section{Results and Discussion \\ Number of Essays and Running Words}

A corpus consisting of 50 essays was compiled for this study. Table 1 shows the number of the essays and the total number of words for all the essays. In total, the learners had written 14,032 words. On average, each learner had written 280 words in each essay.

Table 2. The number of essays and running words.

\begin{tabular}{|l|l|}
\hline Number of essays & 50 \\
\hline Number of words & 14032 \\
\hline
\end{tabular}

The learners were asked to write the essay by hand. The essays later were collected and typed in a .txt file format to be used by AntConc. No grammatical, spelling, or other mistake types were corrected when typing the essays into the .txt file.

\section{Frequency and Usage}

One of the most widely-used word-based calculation methods is presenting the frequency ratio in terms of the number of connectors per 1,000,10,000, or 100,000 words; this method was employed in Granger \& Tyson (1996) Altenberg \& Tapper (1998) studies. The averaged normed frequencies (per 10,000 words) of the total of CAs, by Kurd EFL learners of this study, are presented in Table 3. The frequencies of all the 110 CAs are provided in Appendix A.

Table 3. The averaged normed frequency and use of CAs per 10,000 words.

\begin{tabular}{|l|l|}
\hline Corpus size in words & 14032 \\
\hline Number of CAs & 323 \\
\hline CAs per 10,000 words & 230.188 \\
\hline
\end{tabular}

By comparing Kurd EFL results to other studies, the researcher argues that Kurd EFL learners do overuse CAs in their essays. The average use of CAs by Saudi and Turkish EFL learners was 133.6 and 124.62, respectively (Alsharif, 2017 and Güneş, 2017) per 10,000 words. 
The researchers of both studies (Alsharif, 2017 and Güneş, 2017) compared CAs to native speakers and found that Saudi and Turkish EFL learners overused CAs. The results of this study can be used to argue that Kurd EFL learners do overuse CAs in their essay writings.

There might be some reasons why EFL learners overuse CAs in their writings. Xu \& Liu (2012) state that there may be three reasons why adverbials conjuncts are overused, underused, or misused. Students learn them as grammatical markers rather than natural connectors, the exam-driven effect of the Chinese education system, and learners cannot use English as fluently as their mother tongue. In the same vein, some researchers argue that EFL learners use CAs to demonstrate that their writings are coherent; However, this overuse of CAs affect the clarity and coherence of their arguments compared with their native speaker counterparts (Granger \& Tyson, 1996; Altenberg \& Tapper, 1998; Lei, 2012; Alsharif, 2017). As a result, it can be stated EFL learners demonstrate coherence at the word level while, for native speakers, the writings are coherent at sentence and argument levels.

\section{Percentage of use of Conjunctive Adverbials by Category}

The data analysis showed that the study participants used more sequential and additive, with a total of 133 and 106 hits, respectively, which accounted for a more significant percentage of use than the other two types. Causal and adversative adverbials accounted for 71 and 26 hits only. The percentage of each adverbial type is shown in Table 4.

Table 4. Percentage of Use of Conjunctive Adverbials by Category

\begin{tabular}{|l|l|l|}
\hline Conjunctive Adverbial Category & Total Hits & Percentage \\
\hline Sequential & 133 & $41.17 \%$ \\
\hline Additive & 94 & $29.10 \%$ \\
\hline Causal & 71 & $21.98 \%$ \\
\hline Adversative & 25 & $7.73 \%$ \\
\hline Total & 323 & $100 \%$ \\
\hline
\end{tabular}

Table 4 reflects that Kurd EFL learners prefer more sequential and additive conjuncts than causal and adversative conjuncts. That is, sequential and additives are overused while causal and adversative conjuncts are underused. These results are very similar to Park's (2013) study. This preference slightly changes compared with the results of EFL learners from some other different language backgrounds. Both Lei's (2012) and An \& Xu's (2018) studies discovered that Chinese EFL learners used more additives, and the results of Güneş's (2017) study also show that Turkish EFL learners prefer more additives. Nevertheless, nearly all EFL learners, compared with the other CA categories, used the fewest number of causal and adversative CAs. As a result, it can be argued that there is a tendency among EFL learners to overuse sequential and additive adverbial conjuncts and underuse causals and adversatives (Xu \& Liu, 2012; Sabzevari et al., 2016; Alsharif, 2017; Lei, 2012).

\section{Most Frequently Used Conjunctive Adverbials}

Table 5 demonstrates the top ten most frequently used conjunctive adverbials. Since two CAs, namely because of and second, were used 12 times each, the table contains 11 CAs. This list accounts for more than half $(70.48 \%)$ of all the CAs used by Kurd EFL learners. It should be noted that although causal CAs were not used frequently by Kurd EFL learners, 'so', which is regarded as a causal CA, accounts for $11.30 \%$ of the total number of used CAs. The list also 
contains CAs from all the four main categories; However, even among the 11 examples of the list, five of them are sequential CAs. These results demonstrate how Kurd EFL learners prefer frequent sequential CAs. These results are in line with (Güneş, 2017)(Xu \& Liu, 2012)(An \& $\mathrm{Xu}, 2018$ ) (Hussein \& Mudhi, 2014) in the fact that the list of mainly used adverbs contains CAs from all the four main categories.

Table 5. Top 10 most used CAs by Kurd EFL Learners

\begin{tabular}{|l|l|l|l|}
\hline CA & Hits & Percentage & Type \\
\hline Also & 42 & $13.00 \%$ & Additive \\
\hline So & 38 & $11.76 \%$ & Causal \\
\hline First & 35 & $10.84 \%$ & Sequential \\
\hline In conclusion & 30 & $9.29 \%$ & Sequential \\
\hline For example & 19 & $5.88 \%$ & Additive \\
\hline Finally & 17 & $5.26 \%$ & Sequential \\
\hline That is & 14 & $4.33 \%$ & Additive \\
\hline Because of & 12 & $3.72 \%$ & Causal \\
\hline Second & 12 & $3.72 \%$ & Sequential \\
\hline Then & 11 & $3.41 \%$ & Sequential \\
\hline However & 6 & $1.86 \%$ & Adversative \\
\hline
\end{tabular}

\section{Positions of Conjunctive Adverbs by Category}

The researchers also analyzed the data to discover what position was more preferred by Kurd EFL learners in their essays. Table 6 below shows each CA category's place and their positions in the sentences they were used.

Table 6. The position of Conjunctive Adverbs by Category

\begin{tabular}{|l|l|l|l|l|}
\hline $\begin{array}{l}\text { Conjunctive Adverbial } \\
\text { Category }\end{array}$ & Initial position & Medial position & Final position & Total \\
\hline Sequential & 117 & 15 & 1 & 133 \\
\hline Additive & 42 & 49 & 3 & 94 \\
\hline Causal & 31 & 40 & 0 & 71 \\
\hline Adversative & 16 & 8 & 1 & 25 \\
\hline Total & 206 & 112 & 5 & 323 \\
\hline Percentage & $63.77 \%$ & $34.67 \%$ & $1.54 \%$ & $100 \%$ \\
\hline
\end{tabular}

The results reflect the tendency to use CAs in the initial position by Kurd EFL learners. More than half $(63.77 \%)$ of the overall CAs were used in the initial place, followed by medial $(34.67 \%)$ and final (1.5\%) positions. These results are in line with Quirk et al. 's (1985) argument, in which they claim the initial position is the norm for most adverbial conjuncts. In contrast, some adverbials are more common in medial or final positions. The results of Table 6 also show that the position of the CAs also depends on their category. Although the initial position is the most commonplace for the overall CAs, additives and causal CAs are more used in the medial place. Then, it can be argued that while most CAs are used in the initial position, depending on their categories, some CAs are still preferred to be used in medial.

\section{Conclusions and Pedagogical Implications}

The present study explored the use of adverbial conjuncts in essays written by Kurd EFL learners at the undergraduate level to discover whether the learners overuse or underuse 
adverbial conjuncts, what adverbial categories are more preferred, and at what positions are mostly preferred.

A corpus consisting of fifty essays written by Kurd EFL learners was compiled for this study. The conclusions indicate that Kurd EFL learners heavily depend on specific conjuncts to link the sentences and then between paragraphs. The results also suggest a tendency to use more sequential and additives than adversative and causal adverbial conjuncts. The overuse tendency confirms explorations of many previous research studies. Still, the strong preference for sequential and additive CAs is worth noting in that it can demonstrate the structure and organization of students' essays. Studying Korean EFL learners' writings, Kang \& Oh (2011) had similar findings and argued that Korean students adopt the "explanation with enumeration" pattern more. This preference can explain why the students in this study prefer sequential CAs. Nevertheless, the list of top-ten most used adverbial conjunctions demonstrated that all four categories were used regardless of language register. The learners heavily relied on some specific examples underused or not used the other examples of the same categories. Of them, also, so, first were identified overused which are listed under different categories whereas likewise, in contrast, and accordingly not used at all.

It was also found that the initial position was the preferable position for the use of adverbial conjuncts. This finding was in line with the results of EFL learners from other first language backgrounds. However, some adverbial conjuncts were more preferred in positions other than the initial position, such as medial or sporadic cases in final positions.

\section{Pedagogical Implication}

The way adverbial conjunctions are used profoundly affects the cohesion and coherence of a piece of writing. As Crew (1990) notes, students need to learn to distinguish conjunctive adverbials semantically. Many misleading lists of so-called interchangeable connections might mislead students to commit errors due to training transfer. Pedagogically, Güneş (2017: 30) suggests, CAs should be taught explicitly "by providing authentic and concrete examples." Therefore, Kurd EFL learners ought to learn the meaning and the use of these adverbials to enrich and make their writings cohesive and persuasive.

Teachers of writing need to focus on connecting connectors in paragraphs and essays by exposing students to various types of language registers and instructing students properly about more authentic uses of CAs. Students need to understand those logical connectors are not just to link sentences together on word level; they connect the ideas; Therefore, they should go through a thinking process before deciding which connectors should be used. As Alsharif (2017) notes, the use of too many CAs does not necessarily imply a piece of writing is coherent. Students need to be instructed to improve their essays' coherence at the content level, not just word level. It is also suggested that the integration of teaching writing and reading is practical (Zhang, 2000).

\section{Suggestions for Further Research}

More extensive corpus-based studies on students' use of CAs, consisting of learners across the region, may be conducted in the future to learn more about the use of CAs by Kurd 
EFL learners. Additionally, studying possible reasons of overuse or underuse of CAs using specific essay types and the relationship between first language and foreign-language writing might yield different results regarding the use of CAs by Kurd EFL learners.

\section{About the Authors}

Awder Raza Aziz is an assistant lecturer of Applied Linguistics and TESOL currently teaching at Translation Techniques Department, Sulaimani Technical Institute, Sulaimani Polytechnic University, and English Department, Komar University of Science and Technology in the city of Sulaimani in the Kurdistan Region of Iraq. He has obtained an MA in Applied Linguistics and TESOL from Newcastle University in the United Kingdom. As an EFL lecturer and researcher, he is interested in applied linguistics, pragmatics, sociolinguistics, and TESOL. https://orcid.org/0000-0002-2137-8788

Rebaz Bahadeen Mohammed Nuri is an assistant lecturer of technical translation at Translation Techniques Department, Sulaimani Technical Institute, Sulaimani Polytechnic University. He holds MA in Applied Linguistics with TESOL from the University of Sheffield UK and a BA in English Language and Literature from the University of Sulaimani. Rebaz has taught a wide range of English language courses to EFL/ESL learners for general and academic purposes. His areas of interest are applied linguistics, technics of translation, and spontaneous translation training. https://orcid.org/0000-0001-7216-466X

\section{References}

Alsharif, M. (2017). The Frequently Used Discourse Markers by Saudi EFL Learners. Arab World English Journal, 8(2), 384-397. https://doi.org/10.24093/awej/vol8no2.28

Altenberg, B., \& Tapper, M. (1998). The use of adverbial connectors in advanced Swedish learners' written English. In S. Granger (Ed.), Learner English on computer (1st ed., pp. 8093). New York: Longman.

An, X., \& Xu, M. (2018). Conjunctive Adverbials in Chinese ESL Postgraduates' Expository Writing. Journal of Language Teaching and Research, 9(6), 1243. https://doi.org/10.17507/jltr.0906.13

Biber, D., Johansson, S., Leech, G., Conrad, S., \& Finegan, E. (1999). Longman Grammar of Spoken and Written English. London: Longman.

Blackemore, D. (1987). Semantic Constraints on Relevance. Oxford: Blackwell.

Celce-Murcia, M., \& Larsen-Freeman, D. (1999). The Grammar Book: An ESL/EFL Teacher's Course (2nd ed.). Boston, MA: Heinle \& Heinle.

Chen, C. W. (2006). The use of connective adverbials in the academic papers of advanced Taiwanese EFL learners. International Journal of Corpus Linguistics, 11(1), 113-130. https://doi.org/https://doi.org/10.1075/ijcl.11.1.05che

Conrad, S. M. (1999). The importance of corpus-based research for language teachers. System, 27(1), 1-18. https://doi.org/https://doi.org/10.1016/S0346-251X(98)00046-3.

Crew, W. (1990). The illogic of logical connectives. ELT Journal, 44(4), 316-325.

Crismore, A. (1980). Student Use of Selected Formal Logical Connectors across School Level and Class Type. Retrieved March 10, 2021, from https://eric.ed.gov/?id=ED203306

Gao, X. (2016). A cross-disciplinary corpus-based study on English and Chinese native speakers' use of linking adverbials in academic writing. Journal of English for Academic Purposes, 24(C), 14-28. https://doi.org/10.1016/j.jeap.2016.08.002 
Granger, S., \& Tyson, S. (1996). Connector usage in the English essay writing of native and nonnative EFL speakers of English. World Englishes, 15(1), 17-27. https://doi.org/https://doi.org/10.1111/j.1467-971X.1996.tb00089.x

Güneş, H. (2017). A corpus-based study of linking adverbials through contrastive analysis of L1/L2 PhD dissertations. International Journal of Curriculum and Instruction, 9(2), 21-38. Retrieved from http://ijci.wcci-international.org/index.php/IJCI/article/viewFile/102/46

Halliday, M. A. K., \& Hasan, R. (1976). Cohesion in English. London: Longman.

Hussein, R. F., \& Mudhi, S. (2014). A Corpus-based Study of Conjunctive Adjuncts in the Writings of Native and Non-native Speakers of English. English Linguistics Research, 3(2), 17-32. https://doi.org/10.5430/elr.v3n2p18

Lee, K. (2013). Korean ESL Learners' Use of Connectors in English Academic Writing. English Language Teaching, 25(2), 81-103. https://doi.org/10.17936/pkelt.2013.25.2.005

Lei, L. (2012). Linking adverbials in academic writing on applied linguistics by Chinese doctoral students. Journal of English for Academic Purposes, 11(3), 267-275. https://doi.org/10.1016/j.jeap.2012.05.003

Liu, D. (2008). Linking adverbials: An across-register corpus study and its implications. International Journal of Corpus Linguistics, 13(4), 491-518. https://doi.org/https://doi.org/10.1075/ijcl.13.4.05liu

Milton, J. C. P., \& Tsang, E. S.-C. (1993). A corpus-based study of logical connectors in EFL students' writing : directions for future research. Studies in Lexis, 215-246. Retrieved from http://hdl.handle.net/1783.1/1083

Park, Y.-Y. (2013). How Korean EFL Students Use Conjunctive Adverbials in Argumentative Writing. English Teaching, 68(4), 263-284. https://doi.org/10.15858/engtea.68.4.201312.263

Peacock, M. (2010). Linking adverbials in research articles across eight disciplines. Iberica, 20, 9-34.

Qaddumi, Muhammad K.H. (1995) Textual deviation and coherence problems in the writings of Arab students at the University of Bahrain: sources and solutions. PhD thesis, University of Nottingham.

Quirk, R., Greenbaum, S., Leech, G., \& Svartvik, J. (1985). A Comprehensive Grammar Of The English Language (2nd ed.). New York: Longman.

Rustipa, K. (2014). The Pedagogical Implications of Coherence in English Argumentative Discourse by Indonesian Professionals. Excellence in Higher Education, 4(1), 40-52. https://doi.org/10.5195/ehe.2013.80

Sabzevari, A., Haghverdi, H., \& Biria, R. (2016). Sentence-Initial Conjunctive Adverbials in Academic Articles Written by Native English Speakers and Iranian Efl Writers. Modern Journal of Language Teaching Methods, 6(5), 282.

Salih, R. R. (2014). A COMPARATIVE STUDY OF ENGLISH AND KURDISH CONNECTIVES IN NEWSPAPER OPINION ARTICLES. Riga: LAP LAMBERT Academic Publishing.

Suleiman, H. H., \& Seyyedi, K. (2020). Additive Discourse Markers in English Journal Articles Written by Kurdish and English Native Speakers: A Corpus-Based Study. International Journal of Linguistics, Literature and Translation (IJLLT), 3(1), 56-68. https://doi.org/10.32996/ijllt.2020.3.1.7

Tankó, G. (2004). Composition: The use of adverbial connectors in Hungarian university students' argumentative essays. In J. M. Sinclair (Ed.), How to use corpora in language teaching (12th ed., pp. 157-181). https://doi.org/https://doi.org/10.1075/scl.12.13tan 
Tufte, V. (2006). Artful Sentences: Syntax as Style. Cheshire: Graphics Press LLC.

Wu, H. (2019). A Corpus-based Analysis of TESOL EFL Students' Use of Logical Connectors in Spoken English. Theory and Practice in Language Studies, 9(6), 625. https://doi.org/10.17507/tpls.0906.04

$\mathrm{Xu}, \mathrm{Y} .$, \& Liu, Y. (2012). The use of adverbial conjuncts of Chinese EFL learners and native speakers-corpus-based study. Theory and Practice in Language Studies, 2(11), 2316-2321. https://doi.org/10.4304/tpls.2.11.2316-2321

Yang, A. W. (1989). Cohesive chains and writing quality. Word, 40(1-2), 235-254. https://doi.org/https://doi.org/10.1080/00437956.1989.11435806

Yilmaz, E., \& Dikilitas, K. (2017). EFL Learners' Uses of Adverbs in Argumentative Essays. Novitas-ROYAL (Research on Youth and Language), 11(1), 69-87.

Zhang, M. (2000). Cohesive features in the expository writing of undergraduates in two Chinese universities. RELC Journal, 31, 61-95.

\section{Appendix A: The Frequencies of All the 110 CAs}

A.1. The Frequencies of Additive CAs

\begin{tabular}{|l|l|}
\hline Additive CAs & Frequency \\
\hline Emphatic & 0 \\
\hline Above all & 0 \\
\hline Additionally & 0 \\
\hline Again (sentence initial) & 42 \\
\hline $\begin{array}{l}\text { Also (sentence initial) (in "and also" } \\
\text { (in "not only...but also") (in "but also" } \\
\text { independently) }\end{array}$ & \\
\hline As I/you/we say & 0 \\
\hline As well & 0 \\
\hline As a matter of fact & 0 \\
\hline Besides & 0 \\
\hline In addition (to) & 5 \\
\hline Further & 0 \\
\hline Furthermore & 2 \\
\hline Moreover & 1 \\
\hline Not to mention & 0 \\
\hline Of course & 2 \\
\hline To crown it all & 0 \\
\hline To cap it all & 0 \\
\hline Too & 3 \\
\hline What's (is) more & 0 \\
\hline Subtotal & 55 \\
\hline Apposition/ reformulation & \\
\hline i.e. & 0 \\
\hline That is & 14 \\
\hline That is to say & 0 \\
\hline In other words & 1 \\
\hline For example & 19 \\
\hline For instance & 5 \\
\hline For one (another) thing & 0 \\
\hline Namely & 0 \\
\hline To put it another way & 0 \\
\hline To put it bluntly /mildly & 0 \\
\hline & \\
\hline
\end{tabular}


Arab World English Journal (AWEJ) Volume 12. Number 2. June 2021

Iraqi Kurd EFL Learners' Uses of Conjunctive Adverbials in Essays

Aziz \& Nuri

\begin{tabular}{|l|l|}
\hline What I'm saying is & 0 \\
\hline That is to say & 0 \\
\hline What I mean is & 0 \\
\hline Which is to say & 0 \\
\hline Subtotal & 39 \\
\hline Similarity comparative & \\
\hline Alternatively & 0 \\
\hline By the same token & 0 \\
\hline Correspondingly & 0 \\
\hline Likewise & 0 \\
\hline Similarly & 0 \\
\hline Subtotal & 0 \\
\hline Additives total & 94 \\
\hline
\end{tabular}

A.2. The Frequencies of Adversative CAs

\begin{tabular}{|l|l|}
\hline Adversative CAs & Frequency \\
\hline $\begin{array}{l}\text { Proper adversative /Concessive } \\
\text { while) }\end{array}$ & 2 \\
\hline However & \\
\hline Nevertheless & 6 \\
\hline Nonetheless & 0 \\
\hline Of course & 0 \\
\hline Then again & 2 \\
\hline Though (including contrastive meaning) & 0 \\
\hline Yet (sentence initial) (after a comma) (in \\
"and yet...") (in other position) & 2 \\
\hline Subtotal & 1 \\
\hline Contrastive & 13 \\
\hline Actually & \\
\hline As a matter of fact & 0 \\
\hline Conversely & 0 \\
\hline In/by comparison & 0 \\
\hline In/by contrast & 0 \\
\hline In fact & 0 \\
\hline In reality & 1 \\
\hline On the other hand & 0 \\
\hline Subtotal & 3 \\
\hline Correction & 4 \\
\hline Instead & \\
\hline On the contrary & 4 \\
\hline Rather, & 0 \\
\hline Subtotal & 1 \\
\hline Dismissal & 5 \\
\hline Admittedly & \\
\hline After all & 0 \\
\hline All the same (often used with but) & 1 \\
\hline Anyhow & 0 \\
\hline Anyway & 0 \\
\hline At any rate & 0 \\
\hline Despite/this/that & 0 \\
\hline In any case & 0 \\
\hline In spite of this/that/etc & 0 \\
\hline ord English Journal & 1 \\
\hline & \\
\hline
\end{tabular}

Arab World English Journal

ISSN: 2229-9327 
Arab World English Journal (AWEJ) Volume 12. Number 2. June 2021

Iraqi Kurd EFL Learners' Uses of Conjunctive Adverbials in Essays

Aziz \& Nuri

\begin{tabular}{|l|l|}
\hline Still, & 1 \\
\hline Subtotal & 3 \\
\hline Adversative total & 25 \\
\hline
\end{tabular}

A.3. The Frequencies of Causal/Resultative

\begin{tabular}{|l|l|}
\hline Causal/ Resultative CAs & Frequency \\
\hline General causal & \\
\hline Accordingly, & 0 \\
\hline As a consequence (of) & 0 \\
\hline As a result (of) & 4 \\
\hline Because of it/this/that & 12 \\
\hline Consequently & 0 \\
\hline In consequence & 0 \\
\hline Hence & 0 \\
\hline Naturally (sentence initial) & 0 \\
\hline $\begin{array}{l}\text { So (sentence initial) (after a comma) } \\
\text { (In "and so" not sentence initial) }\end{array}$ & 38 \\
\hline Therefore & 3 \\
\hline Thus & 1 \\
\hline Subtotal & 58 \\
\hline Conditional causal & \\
\hline All things considered & 0 \\
\hline In such a case/cases & 0 \\
\hline In that case & 0 \\
\hline Then (often used with "if") & 11 \\
\hline Otherwise & 2 \\
\hline Subtotal & 13 \\
\hline Causal total & 71 \\
\hline
\end{tabular}

A.4. The Frequencies of Sequential CAs

\begin{tabular}{|l|l|}
\hline Sequential CAs & Counts \\
\hline Enumerative/listing & \\
\hline Afterwards & 0 \\
\hline Eventually (sentence initial) & 0 \\
\hline First/firstly & 35 \\
\hline First and foremost & 0 \\
\hline First of all & 11 \\
\hline In the first place (sentence initial) & 0 \\
\hline To begin with & 0 \\
\hline Second/secondly & 12 \\
\hline Third/thirdly & 3 \\
\hline Fourth/fourthly & 2 \\
\hline Finally (sentence initial) & 17 \\
\hline Last/lastly & 3 \\
\hline Last but not least & 0 \\
\hline Last of all & 0 \\
\hline Next & 3 \\
\hline $\begin{array}{l}\text { Then (sentence initial) (in "and then" } \\
\text { sentence initial) }\end{array}$ & 11 \\
\hline Subtotal & 97 \\
\hline Simultaneous & \\
\hline
\end{tabular}


Arab World English Journal (AWEJ) Volume 12. Number 2. June 2021

Iraqi Kurd EFL Learners' Uses of Conjunctive Adverbials in Essays

Aziz \& Nuri

\begin{tabular}{|l|l|}
\hline At the same time & 2 \\
\hline In the meantime (sentence initial) & 0 \\
\hline Meanwhile & 0 \\
\hline Subtotal & 2 \\
\hline Summative & \\
\hline All in all & 0 \\
\hline In a word & 1 \\
\hline In conclusion & 30 \\
\hline In short & 0 \\
\hline In summary/sum & 0 \\
\hline To conclude & 1 \\
\hline To sum up & 2 \\
\hline To summarize & 0 \\
\hline Subtotal & 34 \\
\hline Transitional to another topic, etc. & \\
\hline By the by & 0 \\
\hline By the way & 0 \\
\hline Incidentally & 0 \\
\hline Subtotal & 0 \\
\hline Sequential total & 133 \\
\hline
\end{tabular}

